\title{
Factors That Determine the Growth of Micro and Small Enterprises: In the Case of Hawassa City, Ethiopia
}

\author{
Demisew G. Degefu \\ Department of Statistics, Hawassa University, Hawassa, Ethiopia \\ Email: demisewgebru@yahoo.com
}

How to cite this paper: Degefu, D.G. (2018) Factors That Determine the Growth of Micro and Small Enterprises: In the Case of Hawassa City, Ethiopia. iBusiness, 10, 185-200.

https://doi.org/10.4236/ib.2018.104011

Received: November 6, 2018

Accepted: December 3, 2018

Published: December 6, 2018

Copyright $\odot 2018$ by author and Scientific Research Publishing Inc. This work is licensed under the Creative Commons Attribution International License (CC BY 4.0).

http://creativecommons.org/licenses/by/4.0/

\section{(c) (i) Open Access}

\begin{abstract}
Micro and small-scale enterprises have key roles to ensure economic growth and reduce poverty in developing countries. This study was conducted on Hawassa City to investigate factor determining the growth of Micro and Small-Scale Enterprise on metal, wood processing, brocket production sector and other enterprise. Primary data is collected from 95 respondents using well-organized self-administered questionnaire. To analyze the data, the researcher used descriptive statistics like frequency tables, graphs and other summary statistics, and regression analysis. In this study capital change is used as a measure of growth of micro \& small-scale enterprise. After the establishment of their business, respondents can produce 66.4 thousand Birr on average. Based on the regression analysis, capital change is significantly determined by explanatory variable like age of respondent, sex of respondent, government motivation, educational level, financial access, and adequate infrastructure.
\end{abstract}

\section{Keywords}

Micro and Small-Scale Enterprise, Capital Change, Linear Regression

\section{Introduction}

In this time, generating economic growth in developing countries while reducing poverty is fundamental challenge. To ensure that the contribution of micro enterprises to key sub sectors and national economies should be maximized, and ensure that the poor should not left out of economic development, micro and small-scale enterprise need access to finance, business services and improved input. They also need a conductive enabling environment that facilitates rather 
than inhibits their participation in markets. Micro and small-scale enterprises in Ethiopia are extremely dominative and socially in efficient. Its greatest asset is the desire to survive and eventually get rich. The other advantage is its creativity and ingeniousness. The small-scale enterprises by no means a homogenous late, consequently the support should be differentiated and properly given to the disparity groups. The farmers are the leaders since they are the primary initiators of change in terms of producing new goods and new ways of production. But, these innovators and drivers must get support and have access to the constituent of elements to effectively utilize their creative capacity and translate their vision into reality [1].

One of the major consequences of rapid urbanization process has been the burgeoning supply of job seekers in both modern (formal) and informal sectors of the urban economy. In many developing countries the supply of workers far exceeds the demand. These result in an extremely high rate of unemployment and under employment in urban areas [2].

In their model, Todaro and Smith [2] emphasized the need for coordinating the effort of different enterprises in order to maximize the benefit they can generate from the economic activity. Ehresman [2] proposed the concept of total quality management which is essential for the success of small business. Before getting into implementation we need to get organized [3]. For successful implementation of total quality management, small businesses need to follow a structure [3].

Human resources of employees are important for managements and organizational science but they are widely ignored in small-scale entrepreneurs. An efficient utilization of employee's skills, motivation and behaviors is essential for business success [4].

In their study Rauch and Frese [4] emphasizes the need for human resource management's strategies for the success of small business. Size of employment, capital investment or turnover is used as criteria to categorize enterprises along scale of operation and define micro, small, medium and large enterprises.

The history of small business (enterprises) has been one of the most controversial stories in economic development in the world. The role of small business in an economy has frequently been undermined and even misinterpreted. In the past, small businesses were believed to impede economic growth by attracting scarce resources from their larger counterparts [5].

Ethiopian government has recognized the contribution of the informal sector. It has been recognized and pay attention to the promotion and development of micro and small-scale enterprise. They are important vehicles to address the challenges of unemployment, economic growth of the country. To this effect, national micro and small-scale enterprise development and promotion strategies has formulated in 1997, which enlightens a systematic approach to alleviate problems and promote the growth of micro and small-scale enterprise. The overall objective of the strategy is to create an enabling environment for micro and small-scale en- 
terprise with specific objective to facilitate economic growth, create long term jobs, strength cooperation between micro and small-scale enterprise, promote export and balances preferential treatment between micro and small-scale enterprise and bigger enterprises [6].

Economic policies, strategies and legal and regulatory frame work are prerequisite in order to create a conducive environment to promote Micro and small-scale enterprise. In Ethiopia deliberate effort to promote micro and small-scale enterprise is started in relatively a recent phenomenon. During the Derg regime due to its ideology, policies and regulations, the environment was not conducive for the private sector. Restrictive polices favoring state organization in availing foreign exchange and bank loans, limits on single borrower loans, restriction on license and investment, absolute priority given to the public sector in access to trained qualified manpower etc. were in place. In general, during the Derg regime the legal requirements to obtain license were bureaucratic and discouraged the participation of enterprise operators. There was tight foreign exchange control and heavy import and rent seeking business community [7]. The $1997 \mathrm{Na}$ tional Micro and small-scale enterprise strategy figure out the various policies, structural and institution related problems that constrained the role of the micro sector and contribution to national economy. It thus primarily aims at creation enabling legal, institutional and other supportive environments for the development of National Micro and small-scale enterprise.

Large and medium scale manufacturing enterprises have been classified as establishments with $>10$ employees using automated machinery. Small and medium scales are those enterprises that engage $<10$ persons using power driven machinery. Cottage are those household type enterprises located in household normally using own or family labor and mostly manual rather than automated or mechanical machinery. In light with the above definitions, the Ethiopian micro, small and medium enterprises are business activities that are independently owned and operated, have small share of the market and are managed by the owner and employing 5 or less employees. This has recently been revised to include employment up to 10 workers and capital reaching up to 20,000 Birr. Small-scale enterprises are those enterprises that employ 6 - 49 employees and they share the characteristics with micro enterprises in other aspects. Medium enterprises are those enterprises which have relatively higher share of the market, are independently or jointly owned and managed by the owners or appointed executives and employees (50 - 99)\% [1].

In most fast developing countries, micro and small-scale enterprise by virtue of their size, capital investment and their capacity to generate greater employment have proved powerful proponent effect for economic growth. The sector is also known as instrument bringing about economic transition by efficiently using the skill and talent of people without requesting high level training, capital and sophisticated technology. Moreover, they create job opportunities for a substantial segment of the population. Hence, this is quick remedy for unemployment problem, direct intervention and support of the government crucial to fa- 
cilitate the environment for new job sectors and self-employments. Ethiopia private sector as a whole is a highly dominated by micro and small-scale enterprises which are geared towards satisfying the speeds of low-income groups. Micro and small-scale enterprises sector accounting the bulk of non-agricultural economic activities, are highly concentrating in the production and consumption of textiles, food and beverage processing [1].

Unity is strength, when there is teamwork and collaboration wonderful things can be achieved (Mattie steepened, 1990). It is believed that the urban development policy and strategy, micro and small-scale enterprises are the key in reducing unemployment and poverty in urban areas. The concept of micro finances has been started in Bangladesh. The German Bank was established as a research project on rural economic program to help the low-income groups under the Chicago University in 1978. The central mission was to credit and to give financial services primarily to rural women and disadvantage groups (Paul, B., 1996). As we compared the current situation with the past governance, there is some improvements; however, there are still several factors are affecting the performance of micro and small-scale enterprises such as finance, market condition, technical skill of owners, government action and expansion of illegal business [8].

The external factors that are hindering the growth of MSEs include access to financial services, access to infrastructure, and access to working premises [9]. Access to working premise, access to credit and access to infrastructure are found significant in determining the probability of MSEs growth from external factors [10], financial access, market access and social network influence the growth of dairy SMEs in Gatundu South. Entrepreneurs have difficulties in accessing finance. Creativity and product development in entrepreneurial skills influenced growth of enterprise to a great extent [11]. Study concluded in Limuru Town Market, Kenya indicates that access to finance and availability of management experience are the key socio-economic factors affecting the performance of businesses in. The other key factors that were found to affect businesses in Limuru Town Market are access to business information, access to infrastructure and government policy and regulations [12]. Access to finance and management skills had positive effect on performance of SMEs but infrastructure didn't significantly affect performance of SMEs in the study area. The results also indicated that as number of years in operations increased the performance [13].

\section{Methodology}

\subsection{Method of Data Collection}

The method of data collection would be determined by factors such as objective of the study, nature of information, operational cost and so on. Based on its origin, statistical data can be classified as primary \& secondary data. This research project was conducted using primary source of data since there is no secondary 
data on the variables included in the study. Basically, there are different methods of collecting primary data. Among these methods self-administrated questionnaire was used to collected information from respondents in this study. The advantage of self-administrated questionnaire is that it avoids interviewer bias and increase confidentiality. The questionnaire has twenty-three question which includes four demographic information seeking questions, sixteen capital related questions, one tax related and two manpower related questions.

\subsection{Sampling Method and Sample Size Determination}

Stratified random sampling is often used when the population is split into subgroups or "strata". The different subgroups are believed to be very different from each other, but it is thought that the individuals who make up each subgroup are similar. In this study, the respondents are divided in to four strata i.e. metal work entrepreneurs, construction work entrepreneurs, wood work entrepreneurs and food production entrepreneurs. This stratification is necessary because respondents working in different sectors face different challenges and they need different amount of capital. To determine the sample size, the researcher used the following stratified random sampling formula (Table 1).

$$
\begin{gathered}
n_{0}=\frac{\sum W_{h} S_{h}^{2}}{V} \text { where, } V=\frac{d^{2}}{Z_{\alpha / 2}^{2}}=\frac{(1.11)^{2}}{(1.96)^{2}}=0.321 \\
n_{0}=\frac{(895 / 2395)(145)+(400 / 2395)(96)+(750 / 2395)(110)+(350 / 2395)(110)}{0.321} \\
=97.996 \sim 98 \\
n=\frac{n o}{1+n o / N}=\frac{98}{1+98 / 2395}=94.15 \sim 95
\end{gathered}
$$

Using proportional allocation, the sample size for each stratum, $n_{h}$ was calculated as follow:

$$
N_{1}=895, N_{2}=96, N_{3}=750, N_{4}=350, n_{h}=\frac{N_{h}}{N} * n
$$

where,

$Z_{\alpha} / 2$ = Critical Value for standard normal variable, usually 1.96 taken for $5 \%$ level of significance.

$S_{i}^{2}=$ Sample variance taken from pilot survey i.e.

$$
S_{1}^{2}=145, S_{2}^{2}=96, S_{3}^{2}=110, S_{4}^{2}=110
$$

Table 1. Population and sample size in each stratum/enterprise.

\begin{tabular}{ccc}
\hline Stratum & Population & Sample Size \\
\hline Food Sector & $N_{1}=895$ & $N_{1} * n / N=n 1=35$ \\
Construction Sector & $N_{2}=400$ & $N_{2} * n / N=n 2=16$ \\
Metal Sector & $N_{3}=750$ & $N_{3} * n / N=n 3=30$ \\
Wood Sector & $N_{4}=350$ & $N_{4} * n / N=n 4=14$ \\
\hline
\end{tabular}




\subsection{Variables in the Study}

\begin{tabular}{|c|c|}
\hline Variable & Description \\
\hline \multicolumn{2}{|r|}{ Dependent variable: } \\
\hline Capital change & The difference between current and beginning capital \\
\hline \multicolumn{2}{|r|}{ Independent variable: } \\
\hline 1) Age & Age of respondents (in years) \\
\hline 2) Sex & Sex of respondents \\
\hline 3) Education & Educational level of respondents \\
\hline 4) Marital status & Marital status of respondents \\
\hline 5) Beginning capital & Beginning capital (in birr) \\
\hline 6) Current capital & Current capital (in birr) \\
\hline 7) Customer visit & Frequency of customer visit \\
\hline 8) Profitability of business & Satisfactions level on profitability of business \\
\hline 9) Receiving feedback & Habit of receiving feedback from customer \\
\hline 10) Government motivation & Motivation give the government \\
\hline 11) Monthly profit & Monthly profit (in birr) \\
\hline 12) Manpower & Number of employees in the sector \\
\hline 13) Number enterprises & Availability of large number of enterprises in the sector \\
\hline 14) $\operatorname{Tax}$ & Percent of tax payment \\
\hline 15) Price & Price of goods \\
\hline 16) Sector & Type of sector \\
\hline 17) Financial access & Financial access \\
\hline 18) Access to market product & Access to market product \\
\hline 19) Infrastructure availability & Adequate infrastructure availability \\
\hline 20) Access to row material & Access to row material \\
\hline 21) Interest rate & Interest rate charged by micro fiancé \\
\hline 22) Technical skill training & Obtain technical skill training from the government \\
\hline
\end{tabular}

\subsection{Methods of Data Analysis}

After careful gathering of the appropriate data using the above instruments the data is analyzed using both inferential statistical and descriptive analysis. Frequency distribution, percentage, measure of central tendencies and measure of variations were used to summarize the data. From inferential analyses linear regression analysis is used.

\subsubsection{Multiple Linear Regression}

The multiple linear regression models are used to study the relation between one dependent variable and two or more explanatory variables. The regression model that involves more than one repressor variables is called multiple linear regression model. Suppose the response variable $\mathrm{Y}$ may be related to $\mathrm{K}$ repressors (explanatory variable). The model's is given by

$$
Y=\beta_{0}+\beta_{1} X_{1 i}+\cdots+\beta_{k} X_{k i}+\varepsilon_{i}
$$




\subsubsection{Analysis of Variance (ANOVA)}

Variability in the regression analysis can be partitioned in to component explained by the regression, SSR and component due to unexplained error, SSRes. That is

$$
S S T=S S R+S S R e S
$$

The overall significance of model is summarized using analysis of variance table (ANOVA).

\subsubsection{F Statistic}

$F$ Statistics is given by

$$
F=\text { MSR } / \text { MSRes }
$$

where $M S R=S S R / k-1 \quad(k-1$ is degrees of freedom explained by regression model) and MSRes $=$ SSRes $/ n-k$ ( $n-k$ is degrees of freedom which are unexplained by the regression model).

\section{Results and Discussion}

The main objective of this study is to identify factor that determines the growth of micro and small-scale enterprises in Hawassa City. The data were collected on 95 respondents using self-administered questionnaire. The analysis was done based on the information and the data obtained from these respondents.

\subsection{Descriptive Analysis}

Among the respondents included in the study (Table 2), 54.7 percent of them are in the age group 15 - 25 years, 35.8 percent of them are in the age group 26 35 years and the rest 9.5 percent of them are in the age group $36-45$ years. Among these respondents, 46.3 percent of them are male and 53.7 percent of them are female. When the researchers see educational background of the respondents, 1.1 percent of them are illiterate, 29.5 percent of them are primary, 40.0 of them are secondary, 16.8 of them are diploma and 12.6 percent of them are degree. Regarding marital status of respondents, about 37.9 percent of them are married, 60.0 of them are single and 2.1 percent of them are divorced.

Among the respondents include in the study (Table 3), 6.3 percent of them were never visited by any customer, 63.3 of them were visited by their customer sometimes, 30.5 percent of them were visited by their customer always. As shown in the above table, 64.2 percent of the respondents have $>5000 \mathrm{Birr}$ monthly profit, 34.7 percent of them have $5001-10,000$ Birr monthly profit and the rest 1.1 percent of them have 10,001 - 50,000 monthly profit. Considering feedback, 98.9 percent of respondents had feedback from their customers and 1.1 percent of them had no any feedback from their customer. Concerning to government motivation, 54.7 percent of the respondent were motivated by the government and 45.3 percent of them were not motivated by the government in their work. Regarding way of motivation, 22.1 percent of the respondents have got finical access, 33.7 percent of them have got training, 1.1 percent of them 
Table 2. Demographic variable.

\begin{tabular}{|c|c|c|c|}
\hline Variable & Category & Frequency & Percent \\
\hline \multirow{4}{*}{ Age } & $15-25$ & 52 & 54.7 \\
\hline & $26-35$ & 34 & 35.8 \\
\hline & $36-45$ & 9 & 9.5 \\
\hline & Total & 95 & 100 \\
\hline \multirow{3}{*}{ Sex } & Male & 44 & 46.3 \\
\hline & Female & 51 & 53.7 \\
\hline & Total & 95 & 100. \\
\hline \multirow{6}{*}{ Education } & Illiterate & 1 & 1.1 \\
\hline & Primary & 28 & 29.5 \\
\hline & Secondary & 38 & 40.0 \\
\hline & Diploma & 16 & 16.8 \\
\hline & Degree and above & 12 & 12.6 \\
\hline & Total & 95 & 100 \\
\hline \multirow{4}{*}{ Marital-Status } & Married & 36 & 37.9 \\
\hline & Single & 57 & 60.0 \\
\hline & Divorced & 2 & 2.1 \\
\hline & Total & 95 & 100 \\
\hline
\end{tabular}

have got other type of motivation, but 43.23 percent of them didn't give any response about the motivation they obtained. Moreover, 64.2 percent of the respondents agree with existence of large number of enterprise in their sector but the rest 35.8 percent of them didn't agree with the existence of large number of enterprise in their sector.

From Table 4 below, 9.5 percent of the respondents strongly disagree with financial access, 41.1 percent of them disagree with finical access, 8.4 percent of them are neutral on finical access, 40.0 percent of them agree with finical access and 1.1 percent of them are strongly agree with finical access on their business. Similarly, 7.4 percent of the respondents strongly disagree with access to market, 26.3 percent of them disagree with access to market, 6.3 percent of them didn't decide on access to market, 57.8 percent of them agree with access to market and the rest 2.2 percent of them strongly agree with access to market. In same manner, 16.8 percent of the respondents strongly disagree with adequate infrastructure, 64.2 percent of them disagree with adequate infra-structure, 3.0 percent of them didn't decided with adequate infra-structure, 14.0 percent of them agree with adequate infrastructure and the rest 1.0 percent of them strongly agree with adequate infrastructure. Moreover, 6.3 percent of the respondents strongly disagree with access to necessary row material., 31.6 percent of them disagree with access to necessary row material, 5.3 percent of them didn't decided on access to necessary row material, 55.9 percent of them agree with access to necessary row 
Table 3. Capital change related variable.

\begin{tabular}{|c|c|c|c|}
\hline Variable & Category & Frequency & Percent \\
\hline \multirow{4}{*}{ Customer visit } & Never & 6 & 6.3 \\
\hline & Sometimes & 60 & 63.3 \\
\hline & Always & 29 & 30.5 \\
\hline & Total & 95 & 100 \\
\hline \multirow{4}{*}{ Monthly profit } & $>5000$ & 61 & 64.2 \\
\hline & $5001-10,000$ & 33 & 34.7 \\
\hline & $10,001-50,000$ & 1 & 1.1 \\
\hline & Total & 95 & 100 \\
\hline \multirow{4}{*}{ Profitable of your business } & Unsatisfactory & 26 & 27.4 \\
\hline & Average & 43 & 45.3 \\
\hline & Satisfactory & 26 & 27.4 \\
\hline & Total & 95 & 100 \\
\hline \multirow{3}{*}{ Feedback } & Yes & 94 & 98.9 \\
\hline & No & 1 & 1.1 \\
\hline & Total & 95 & 100 \\
\hline \multirow{3}{*}{ Government motivation } & Yes & 52 & 54.7 \\
\hline & No & 43 & 45.3 \\
\hline & Total & 95 & 100 \\
\hline \multirow{5}{*}{ Ways of motivation } & Financial & 21 & 22.1 \\
\hline & Training & 32 & 33.7 \\
\hline & Other & 1 & 1.1 \\
\hline & Missing & 45 & 43.23 \\
\hline & Total & 95 & 100 \\
\hline \multirow{3}{*}{ Number of enterprises } & Yes & 61 & 64.2 \\
\hline & No & 33 & 35.8 \\
\hline & Total & 94 & 100 \\
\hline \multirow{3}{*}{$\begin{array}{l}\text { The price of good have } \\
\text { impact on your business }\end{array}$} & Yes & 88 & 97.6 \\
\hline & No & 3 & 2.4 \\
\hline & Total & 91 & 100 \\
\hline
\end{tabular}

material and 1.0 percent of them are strongly agree. The remaining variables can be interpreted in similar manner.

The average change in the current and previous capital for micro and small-scale enterprises in this study is about 66.4 thousand Birr with standard deviation 124 (Table 5). The minimum capital change is found to be -480 thousand Birr and the maximum capital change is 570 thousand Birr. The average percentage tax payment for micro and small-scale enterprise is 3.39 thousand Birr with standard deviation 4.0327. The minimum percentage tax payment is found to be one thousand Birr and the maximum percentage tax payment is 25 thousand Birr. The average of pervious manpower in micro and small-scale 
Table 4. Capital change related variable.

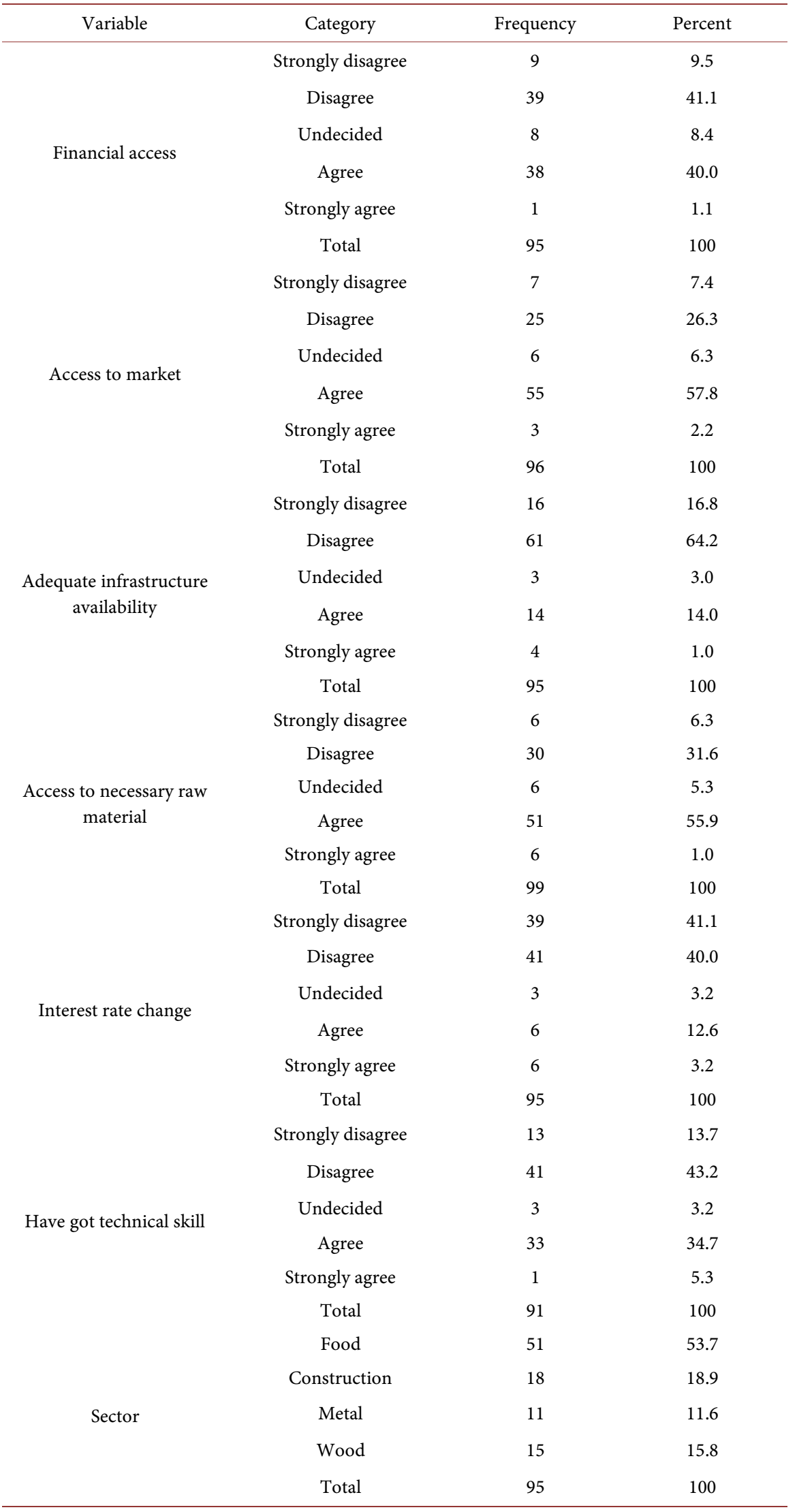


Table 5. Summary statistics for selected continuous variables.

\begin{tabular}{cccccc}
\hline Variables & N & Minimum & Maximum & Mean & Std. Deviation \\
\hline Capital Change (in 1000 Birr) & 94 & -480.00 & 570.00 & 66.4149 & 124.00567 \\
Percentage Tax Payment & 83 & 1 & 25 & 3.39 & 4.078 \\
Previous Manpower & 94 & 3 & 7 & 4.98 & 0.327 \\
Current Manpower & 95 & 1 & 8 & 4.95 & 1.672 \\
\hline
\end{tabular}

enterprise is 4.98 with standard deviation 0.327 . The minimum pervious manpower is 3 and the maximum pervious manpower 7. The average of current manpower is 4.95 with standard deviation. The minimum current manpower is 1 and the maximum current manpower is 8 .

\subsection{Linear Regression Analysis}

\subsubsection{Model Summary}

Model summary is shown in Table 6. The value of adjusted R Square (0.613) indicates that $61.3 \%$ variation in capital change is due to the independent variables included in the model. When the correlation between the errors is close to zero, the Durbin-Watson statistic will close to 2. The Durbin-Watson statistic in the above table is 2.205 . This implies that there is no autocorrelation between the errors.

\subsubsection{Testing Overall Significance of the Model}

Based on the below analysis of variance table (Table 7) the researcher tested overall test of the regression model. From the above ANOVA table, P-Value is 0.000 is less than the commonly used level of significant $(0.05)$. So, the researcher can conclude that there is at least one independent variable in the regression model that can determine the dependent variable, capital change.

\subsubsection{Parameter Estimation}

As displayed in Table 8, the relationship between the 12 independent variables and capital change in the following regression model.

$$
\begin{aligned}
Y i= & 22.83-91.78 X_{1}-87.52 X_{2}+99.0 X_{3}+57.75 X_{4}+100.27 X_{5}+83.71 X_{6} \\
& +123.9 X_{7}+99.41 X_{8}+91.98 X_{9}-91.74 X_{10}-85.28 X_{11}+64.51 X_{12}
\end{aligned}
$$

where,

$$
\left.X_{1}=\text { Age } 1 \text { (Age }=1 \text { for } 26-35 \text { years and Age }=0 \text { Otherwise }\right) .
$$

$X_{2}=$ Edu 2 (If the respondent's educational level is Secondary coded as 1, otherwise 0).

$X_{3}=$ Edu 4 (If the respondent's educational level is Degree and above coded as 1 , otherwise 0$)$.

$X_{4}=$ Marital 2 (If the respondent's marital status is Single coded as 1, otherwise 0 ).

$X_{5}=$ Construction (If the respondent's Business Sector is Construction coded as 1 , otherwise 0 ). 
Table 6. Model summary.

\begin{tabular}{ccccc}
\hline $\mathrm{R}$ & $\mathrm{R}$ Square & Adjusted R Square & Std. Error of the Estimate & Durbin-Watson \\
\hline $0.823^{\mathrm{ab}}$ & 0.677 & 0.613 & 84.45231 & 2.205 \\
\hline
\end{tabular}

Table 7. Test of overall significance.

\begin{tabular}{ccccccc}
\hline \multicolumn{7}{c}{ ANOVA $^{\mathrm{a}}$} \\
\hline Model & Sum of Squares & Df & Mean Square & F & Sig. \\
\hline \multirow{2}{*}{28} & Regression & 910970.385 & 12 & 75914.199 & 10.644 & $0.000^{\mathrm{b}}$ \\
& Residual & 435063.737 & 61 & 7132.192 & & \\
& Total & 1346034.122 & 73 & & & \\
\hline
\end{tabular}

a. Dependent Variable: Capital-change. b. Predictors: (Constant), sex of respondents, Finance 2, Edu 4, Infrastructure 3, Marital 2, Finance 1, government motivates your business operation in the town, Age 1, Construction, Infrastructure 2, Finance 3, Edu 2.

Table 8. Linear regression parameter estimation.

\begin{tabular}{|c|c|c|c|c|c|c|c|}
\hline & \multicolumn{2}{|c|}{$\begin{array}{c}\text { Unstandardized } \\
\text { Coefficients }\end{array}$} & \multirow{2}{*}{$\begin{array}{c}\text { Standardized } \\
\text { Coefficients } \\
\text { Beta }\end{array}$} & \multirow{2}{*}{$\mathrm{T}$} & \multirow{2}{*}{ Sig. } & \multicolumn{2}{|c|}{$\begin{array}{c}\text { Collinearity } \\
\text { Statistics }\end{array}$} \\
\hline & B & Std. Error & & & & Tolerance & VIF \\
\hline (Constant) & 22.830 & 71.996 & & 0.317 & 0.752 & & \\
\hline Age 1 & -91.784 & 26.209 & -0.325 & -3.502 & 0.001 & 0.616 & 1.624 \\
\hline Edu 2 & -87.516 & 22.962 & -0.323 & -3.811 & 0.000 & 0.740 & 1.352 \\
\hline Edu 4 & 99.004 & 33.943 & 0.228 & 2.917 & 0.005 & 0.868 & 1.153 \\
\hline Marital 2 & 57.752 & 24.088 & 0.203 & 2.397 & 0.020 & 0.743 & 1.347 \\
\hline Construction & 100.271 & 26.062 & 0.313 & 3.847 & 0.000 & 0.802 & 1.247 \\
\hline Finance 1 & 83.709 & 44.257 & 0.310 & 1.891 & 0.063 & 0.197 & 5.066 \\
\hline Finance 2 & 123.899 & 55.260 & 0.251 & 2.242 & 0.029 & 0.424 & 2.361 \\
\hline Finance 3 & 99.407 & 45.740 & 0.357 & 2.173 & 0.034 & 0.196 & 5.106 \\
\hline Infrastructure 2 & 91.981 & 55.001 & 0.135 & 1.672 & 0.100 & 0.819 & 1.221 \\
\hline Infrastructure 3 & -91.738 & 37.780 & -0.222 & -2.428 & 0.018 & 0.632 & 1.582 \\
\hline Sex of respondents & -85.276 & 25.054 & -0.316 & -3.404 & 0.001 & 0.615 & 1.627 \\
\hline $\begin{array}{c}\text { Government motivates } \\
\text { your business }\end{array}$ & 64.509 & 23.703 & 0.238 & 2.722 & 0.008 & 0.691 & 1.448 \\
\hline
\end{tabular}

a. Dependent Variable: Capital-change.

$\mathrm{X}_{6}=$ Finance 1 (If the respondent disagrees with financial access coded as 1 , otherwise 0 ).

$\mathrm{X}_{7}=$ Finance 2 (If the respondent neutral with financial access coded as 1 , otherwise 0 ).

$\mathrm{X}_{8}=$ Finance 3 (If the respondent agrees with financial access coded as 1, otherwise 0).

$\mathrm{X}_{9}=$ Infrastructure 2 (If the respondent neutral with Adequate Infrastructure access coded as 1 , otherwise 0 ). 
$\mathrm{X}_{10}=$ Infrastructure 3 (If the respondent agrees with Adequate Infrastructure access coded as 1 , otherwise 0 ).

$\mathrm{X}_{11}=$ Sex of respondents $(\mathrm{Sex}=1$ for female respondents and Sex $=0$ for male respondents).

$\mathrm{X}_{12}=$ Government motivates your business (If the government motivates respondent's business coded as 1 , otherwise 0 ).

Backward stepwise variable selection method was adopted to identify significant variables among the bunch of independent variables originally proposed by the researcher. In this study, only twelve dummy variables were significant that determine the capital change. All Variance Inflation Factor (VIF) values were small (smaller than 10), which indicated that there is no serious Multicollinearity problem.

At the 5 percent level of significance, having educational level degree and above, being single, working in construction business sector, getting financial access, getting adequate infrastructure, and getting motivation from the government has positive effect capital change. This result shows the real situation. For example, respondent whose educational level is degree and above higher current capital is relative to the other category. Similarly, respondents who got financial access score higher capital change. The other variable can be interpreted in similar manner. On the contrary, being in the age group 26 - 35 years, having lower educational level (i.e. secondary), and being female have a negative effect on capital change.

The benchmarks for these dummy variables were age 15 - 25, illiterate, married, food sector, strongly disagree with financial access, strongly disagree with adequate infrastructure access, being female and government motivation. All comparisons were made in relation to these categories. The capital change, in this benchmark category was about 22.83. Compared with this, the average capital change for respondents whose age is 26 - 35 was lower by 91.784 (i.e. 22.83 91.784). Similarly, for those respondents having secondary school educational level, average capital change was lower by 87.52 for actual average of -64.69 . On the other hand, for those respondents having degree and above, average capital change was higher by 99 for actual average of 121.83 (i.e. $22.83+99$ ). In the same manner; for those respondents working in construction sector, the average capital change was higher by 100.27 for actual average of 123.1. Likewise, for those respondents who are neutral and agreed with financial access, average capital change was higher by 123.9 and 99.41 for actual average of 146.73 and 122.24 respectively. Regarding sex, for female respondents, average capital change was lower by 85.28 for actual average of 108.11 . The other variable can be interpreted in similar manner.

\subsubsection{Checking Normality of Residuals}

The histogram is approximately symmetrical and in the Normal P-P plot, the points don't deviate from the line (Figure 1, Figure 2). Thus, both the histogram and Normal P-P plot for standardized residual shows that the standardized 


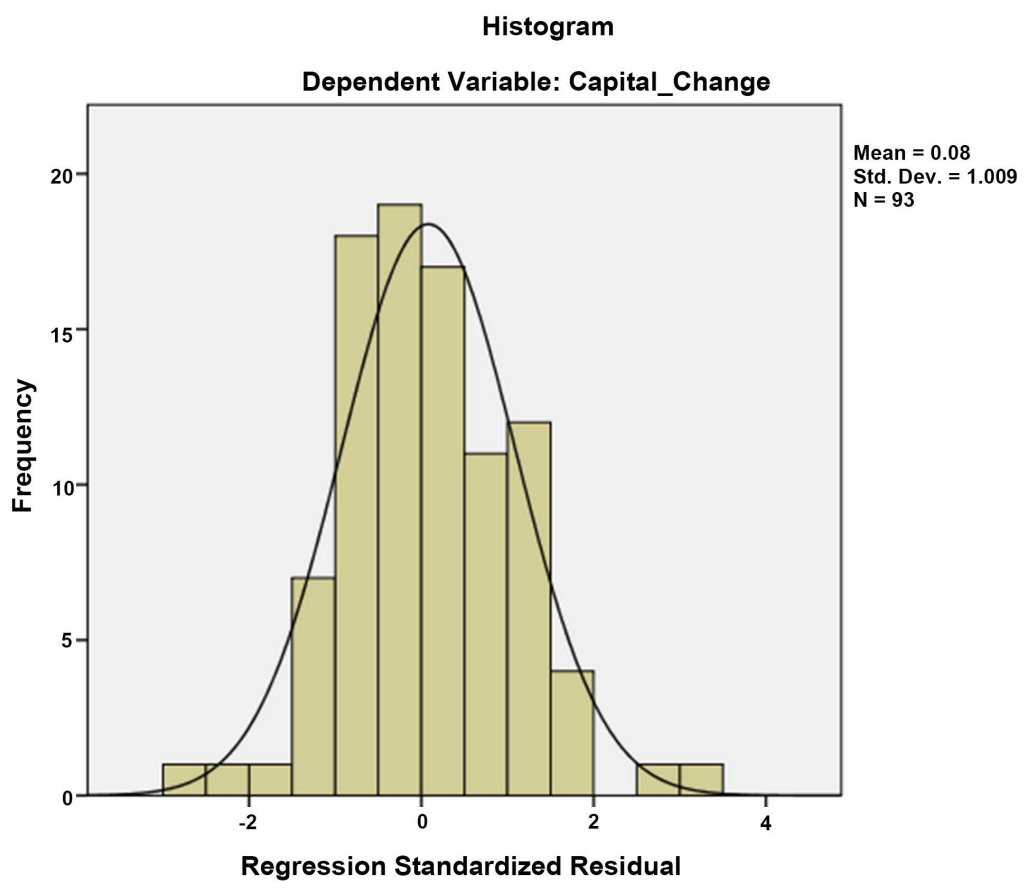

Figure 1. Histogram for standardized residual.

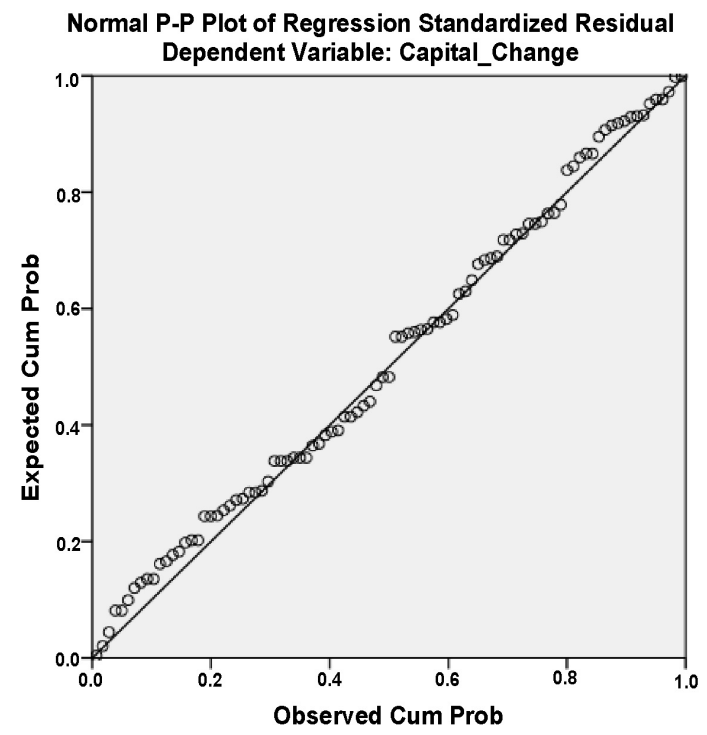

Figure 2. Normal P-P plot for standardized residual.

residuals became normal after fitting the linear regression model. This shows that the model fits the data well.

\section{Conclusion and Recommendation}

\subsection{Conclusion}

The purpose of this study was to determine factors that influence or determine the growth of micro and small-scale enterprise in Hawassa City. From the empirical results, it can be concluded that capital change (i.e. performance of micro 
and small enterprises) is determined by age of the respondent, education level of respondents, marital status of respondents, respondents' involvement in construction sector, respondents' access to finance, respondents' access to adequate infrastructure, sex of respondents and Government motivation. Respondents who have higher educational level have higher current capital relative to their previous capital. Respondents who got financial access also score higher capital change. On the other hand, female respondents have lower capital change compared to male respondents.

\subsection{Recommendation}

Based on the result of the study the following recommendation are forward regarding the Hawassa City Bahel Adarash and Misrak Sub City Micro and Small-Scale Enterprises.

> Government officials in Hawassa City, Bahel Adarash and Misrak Sub City should motivate Micro and Small-Scale Enterprises interprise to increase their capital to be able competent.

Respondents should take time to attend at least first degree in related fields. In this regard, the government should also give learning opportunities for people involved in Micro and Small-Scale Enterprises.

> The government should increase the financial access to motivate and strengthen Micro and Small-Scale Enterprises.

The government should also motivate Micro and Small-Scale Enterprises owner specially, females to increase their capital and to change them to large scale enterprises.

\section{Conflicts of Interest}

The author declares no conflicts of interest regarding the publication of this paper.

\section{References}

[1] Woldie, A. (1989) Small-Scale Enterprise and Development in Ethiopia. 1st Edition, Addis Ababa.

[2] Todaro and Smith (2006) Emphasized the Need for Coordinating the Effort of Different Enterprises in Order to Maximize the Benefit They Can Generate from the Economic Activity.

[3] Ehresman (2008) Purpose the Concept of Total Quality Management Is Essential for the Success of Small Business.

[4] Rauch and Frese (2001) Emphasizes the Need for Human Resource Management's Strategies for the Success of Small Business.

[5] Act and Audretch (1993) Small Businesses Were Believed to Impede Economic Growth by Attracting Scarce Resources from Their Larger Counterparts.

[6] Robert, H. and Jilly, H. (1997) Strength Cooperation between Micro and Small-Scale Enterprise, Promote Export and Balances Preferential Treatment between Micro and Small-Scale Enterprise and Bigger Enterprises.

[7] Gebrehiwot (1997) The National Micro and Small-Scale Enterprise Strategy Figure 
Out the Various Policies, Structural and Institution Related Problems That Constrained the Role of the Micro Sector and Contribution to National Economy.

[8] Negahu (1992) Small-Scale Enterprise and Entrepreneurship Development in Ethiopia. 2nd Edition.

[9] Ishengoma, E. (2006) The Role of Firm-Resources: Performance Differentials between Women- and Men-Owned Micro-Enterprises in Tanzania. University of Leipzig, Tanzania.

[10] Haftom, H.A., Fisseha, G.T. and Araya, H.G. (2014) External Factors Affecting the Growth of Micro and Small Enterprises (MSEs) in Ethiopia: A Case Study in Shire Indasselassie Town, Tigray. European Journal of Business and Management, 6, 134-145.

[11] Kamau, J.M. and John, K.N. (2014) Factors Affecting the Growth of Small and Micro Enterprises Dairy Farmers' in Kenya: Case of Gatundu South Farmer's Dairy Co-Operative Society Ltd, Kenya. International Journal of Current Business and Social Sciences, 1, 48-63.

[12] Mbugua, S.K., Agnes, N. and Ondabu, I.T. (2014) Factors Affecting the Performance of Micro and Small Enterprises in Limuru Town Market Kiambu County, Kenya. International Journal of Scientific and Research Publications, 4, 1-20.

[13] Anne, N.K. (2014) Factors Affecting the Performance of Small and Medium Enterprises in the Jua Kali Sector In Nakuru Town, Kenya. IOSR Journal of Business and Management, 16, 80-93. https://doi.org/10.9790/487X-16148093 